OPEN ACCESS

Edited by: Gianluca Serafini, San Martino Hospital (IRCCS), Italy

Reviewed by:

Eyal Fruchter,

Technion Israel Institute of

Technology, Israel

Marion Trousselard

Institut de Recherche Biomédicale des Armées (IRBA), École du

Val-de-Grâce, EPSAM

APEMAC EA 4360, France

${ }^{*}$ Correspondence:

Zhengzhi Feng

fzz@tmmu.edu.cn

${ }^{\dagger}$ These authors share first authorship

Specialty section: This article was submitted to Mood and Anxiety Disorders,

a section of the journal

Frontiers in Psychiatry

Received: 15 December 2019

Accepted: 04 May 2020

Published: 18 June 2020

Citation:

Wang J, Cheng $X, X u K, X u H$, Wang $H$ and Feng $Z$ (2020) Rejection Sensitivity Mediates the Relationship Between

Social-Interpersonal Stressors and Depressive Symptoms in Military Context.

Front. Psychiatry 11:447. doi: 10.3389/fpsyt.2020.00447

\section{Rejection Sensitivity Mediates the Relationship Between Social- Interpersonal Stressors and Depressive Symptoms in Military Context}

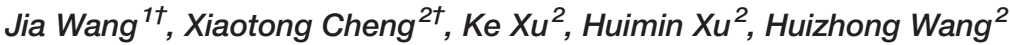 \\ and Zhengzhi Feng ${ }^{1 *}$
}

${ }^{1}$ Department of Developmental Psychology for Armyman, School of Psychology, Army Military Medical University, Chongqing, China, 2 Graduate School, Army Military Medical University, Chongqing, China

Background: Depression is pervasive in the military context and is likely to elicit lasting negative effects on health. Based on interpersonal models, social-interpersonal stressors are significantly associated with the development and maintenance of depression. However, little is known about the mechanisms by which these stressors increase the risk of depression in terms of social relationships. Rejection sensitivity, which refers to people who are sensitive to social rejection and tend to anxiously expect, readily perceive, and overreact to it, may play an underlying role in this process, as it is formed through social-interpersonal stressors and then aggravates further symptoms of depression.

Objectives: The current study aimed to examine the mediating effects on the relationship between social-interpersonal stressors and depressive symptoms in the military context.

Methods: This study recruited 600 soldiers aged from 17 to 36 ( $M=21.80 ; \mathrm{SD}=2.99$; $100 \%$ males) with a cluster sampling method who completed Social-Interpersonal Stressors subscale, Rejection Sensitivity Questionnaire (RSQ), and Self-Rating Depression Scale (SDS). Mediation analyses examined the underlying mechanism between social-interpersonal stressors and depressive symptoms.

Results: The results support the hypothesis and indicate that rejection sensitivity mediates the association between social-interpersonal stressors and depressive symptoms ( $B$ indirect $=0.02, p<0.001,95 \% C l=0.005$ to 0.044 ).

Conclusions: The findings suggest that interventions designed to desensitize individuals' high levels of rejection sensitivity may help to decrease their risk of depressive symptoms in the military environment. Rejection sensitivity is an important mechanism underpinning the development of depressive symptoms. Other theoretical and applied implications for prevention of depressive symptoms in the military context are discussed.

Keywords: social-interpersonal stressors, rejection sensitivity, depressive symptoms, military, mechanism 


\section{INTRODUCTION}

Depression is an important public health problem that has the greatest negative effect on health (1); the worldwide prevalence of MDD (major depressive disorder) was 3\% during the period from 1990 to 2015 (2). Additionally, depression is associated with increased suicide rates, decreased quality of life, and poor social functioning (3). Specifically, in the military context, the impacts of depression can be exacerbated since military populations encounter additional special stressors, which are associated with the high risk of soldiers' mental health deterioration (4), including potential threat or danger, combat exposure, geographical separation, strict hierarchy, conflict between ranks and limited communication with families $(5,6)$. A meta-analysis found the evidence that combat experience substantially increases the risk of depression $(O R=1.60$, $95 \%, C I=1.09-2.35)(7)$. Further, there are a number of studies on the higher prevalence of major depression disorders and symptoms in military settings. For example, Gadermann et al. used 25 epidemiological studies to estimate the prevalence of DSM-IV major depression in U.S. military personnel; the results indicated prevalence rates of $12.0 \%$ among those currently deployed, $13.1 \%$ among those previously deployed and 5.7\% among those never deployed (8). As is revealed by Warne et al., 15.9\% endorsed moderate or more severe current depressive symptoms in U.S. entry-level training soldiers (9). In addition, the prevalence of major depression in Australian Gulf War veterans 20 years after the war was $9.7 \%$ among 697 Gulf War veterans, which was slightly more severe than a military comparison group (7.7\%) (10). According to the 2016 Survey of Mental Disorders in the Republic of Korea, the prevalence of major depressive disorder was $5.0 \%$, which was higher than the global prevalence of depression (3\%), and $8.6 \%$ military officers had depressive symptoms among a sampling of 2047 participants (11). In China, Feng et al. studied 14,000 participants and showed that the prevalence of depressive symptoms in Chinese army men is $18.1 \%$ (12). Interestingly, the incidence varies with deployment exposure as well as operational missions; the prevalence of depressive symptoms in Chinese soldiers ranged from $5.20 \%$ to $51.56 \%(13,14)$. Taken together, there is substantial evidence that military stressors increase the risk of depressive symptoms. Therefore, it is essential to reveal the underlying processes related to depressive symptoms to develop effective clinical strategies, especially in the military context, in which the incidence rates of depressive related disorders and symptoms are significantly higher than in other contexts (15).

According to interpersonal models of depression, socialinterpersonal stressors are crucial risk factors concerning the etiology and course of depression (16-18). Rudlph's (19) research clearly showed that interpersonal stressors are associated with depressive symptoms and that interpersonal processes are involved in the development and perpetuation of depression. In the military settings, tremendous socialinterpersonal stressors could be confronted by soldiers due to their specific environment, such as deployments or operational missions, unfamiliar cultural environment, isolated physical environment, and separation from and communication restrictions with family members (20). Nonetheless, troops are considered as a highly disciplined unit in which soldiers always share living quarters for significant missions or duties during service periods and separate from family members (21). Maintaining these close social bonds with comrades and leaders is essential for organizational morale and effectiveness (22). Furthermore, strains among peers, leaders, and family members, and a lack of support from them, may accelerate depressive symptoms (23-25).

From the perspective of well-established diathesis-stress theories, depression is a result of the interaction between vulnerability or predisposition (diathesis) and life stress (26). On the one hand, numerous social-interpersonal stressors have a long-lasting adverse effect on mental health, especially depression in military settings (7). On the other hand, for depressive individuals, their vulnerability or predisposition and being confronted with social-interpersonal stressors simultaneously account for their depression (26). One of vital predispositions may be rejection sensitivity, in which people who are sensitive to social rejection tend to anxiously expect, readily perceive, and overreact to such rejection (27). Humans tend to develop a sense of belonging to others rather than being rejected or isolated (28). Regarding military personnel under physically restricted and highly concentrated circumstances, to strengthen interpersonal relationships, social connections, and emotional support, avoiding rejection by others, are indispensable (20). Based on attachment theory, when foster parents tend to react to children's needs with rejection or neglect, children will develop insecure working models that are full of anxieties (29). In other words, individuals who suffer from social-interpersonal stressors $(30,31)$, especially those rejected by others, experience a high level of rejection sensitivity (27).

Rejection sensitivity is the core feature of atypical depression (3). Many empirical studies have demonstrated that rejection sensitivity is a risk factor for the etiology of depression (32-34). A meta-analysis review of 43 studies showed that there is a significant association between rejection sensitivity and depression (pooled $r=0.332 ; p<0.001$ ) (35).

Previous studies have investigated the underlying cognitive and neural mechanisms by which social-interpersonal stressors can influence depression. Once individuals experience social defeat or rejection, those who feel a high level of social stress induce a cognitive change that may include negative selfreferential cognitions (27) and elicit biological changes that may evoke depression, including prolonged and higher levels of cortisol reactivity (36), inflammatory responses (37), and dysregulation of the MAX-MYC network in the brain (38). When taking the individuals' the hyper-sensitivity to rejection predisposition into consideration, social-interpersonal stressors may activate differential effects on cognitive pathways and brain regions involved in processing social-interpersonal stress.

Thus, to protect military personnel from depression stemming from overwhelming social-interpersonal stressors, the possible mechanisms related to such depression need to be understood. Although significant relationships among socialinterpersonal stressors, rejection sensitivity, and depression have been shown by numerous empirical studies, few of them 
have directly examined the mediating mechanism. The evaluation of depressive symptoms and their likely severity in military settings and identification of the underlying mechanisms are essential requirements for developing a comprehensive understanding of military depressive symptoms and for developing interventions based on social-interpersonal stressrejection sensitivity for promoting soldiers' mental health and for enhancing unit fitness. Thus, our hypotheses are that the prevalence of depressive symptoms in our cohort was at a higher level in the military context, and rejection sensitivity mediates the association between relational stressors and depressive symptoms.

\section{MATERIALS AND METHODS}

\section{Participants}

The participants were 600 soldiers recruited from armed forces with cluster sampling. The study was approved by the ethics committee of Army Medical University. Participants gave written informed consent before completing the questionnaires. Participation was voluntary and anonymous. Participants had a mean age of $21.80 \pm 2.99$ years; all of them were male; the mean length of military service was $3.46 \pm 2.55$ years; 566 participants were single $(94.40 \%)$, and 34 were married $(5.70 \%)$; and 64 participants had a low education level (10.70\%), 425 had a moderate education level (70.80\%), and 111 had a high education level (18.50\%).

\section{Research Measures \\ Social-Interpersonal Stressors}

The six-item social-interpersonal stressor subscale was chosen to assess the extent to which soldiers were confronted with social stress from leaders, peers, and lovers (39) (e.g., "The relationships with my fellow soldiers were strained. I will contradict my superiors."). In the present study, Cronbach's $\alpha$ coefficient was 0.80 .

\section{Rejection Sensitivity}

Rejection sensitivity was assessed with the Chinese version of the Rejection Sensitivity Questionnaire (RSQ) based on Downey's rejection sensitivity questionnaire (40). The RSQ consists of 18 interpersonal situations in which rejection is possible. Answers to the hypothetical situations varied along two dimensions: (a) the degree of anxiety and concern about the outcome and (b) expectations of acceptance or rejection. Anxiety and expectation were both rated on a 6-point Likert scale, with anxiety rated from 1 (not at all anxious) to 6 (very anxious) and expectation rated from 1 (very unlikely) to 6 (very likely). The rejection sensitivity score was calculated by multiplying the score for the degree of anxiety by the expectation of rejection (expectation of rejection $=$ 7 - expectation of acceptance), and a total score was computed by summing the rejection sensitivity scores for each situation. Internal consistency was $\alpha=0.80$ ), and test-retest reliability was $r=0.89$. In the Chinese version of the RSQ, confirmatory factor analysis indicated that there were three factors involved, namely, leaders' rejection sensitivity, peers' rejection sensitivity, and lovers' rejection sensitivity. The three-factor model fit indices of the Chinese version of the RSQ in the military population were perfect (41). In the current sample, Cronbach's $\alpha$ coefficient was 0.84 , indicating that reliability and validity were good.

\section{Depressive Symptoms}

Depressive symptom was measured using the self-rating depression scale of Zung (42), reflecting four groups of symptoms of depressive states: pervasive psychic disturbance, physiological disturbance, psychomotor disturbance, and psychological disturbance. The scale consists of 20 items, rated 1 (none or a little of the time) to 4 (most or all of the time), ranging from 20 to 80 . Specifically, the scores of the 20 items were added and multiplied by 1.25 to convert them into standard scores. According to the norm for Chinese soldiers (43), scores ranging from 53 to 62 reflect mild depressive symptoms, scores ranging from 63 to 72 reflect moderate depressive symptoms and scores above 72 reflect major depressive symptoms. In the present sample, the scores had high internal consistency $(\alpha=0.80)$.

\section{Procedure}

The survey was guided by a professional psychology researcher. The survey procedure was standard. Participates were asked whether they wanted to complete the survey. Only participants who completed the whole questionnaire were included in the sample. Participants with missing or irregular answers were excluded.

\section{Statistical Analysis}

The descriptive statistics and correlation analyses of the outcome measures were performed using SPSS19.0. The mediation model mentioned in the introduction was tested with structural equation modeling by AMOS 19.0.

All analyses were conducted using SPSS19.0 and AMOS19.0.

The present status of depressive symptoms in soldiers was first tested with ANOVA and $t$ test. Then, Pearson bivariate correlations were calculated to identify intervariable correlations. A simple mediation effect was examined using structural equation modeling.

\section{RESULTS}

\section{Overall Situations of Depressive Symptoms}

According to the depression norm for Chinese soldiers, the prevalence of depressive symptoms in our military cohort was 28.4\%: 148 participants had mild depressive symptoms (24.7\%), 22 participants had moderate depressive symptoms (3.6\%), and 1 participant had major depressive symptoms $(0.2 \%)$. In terms of educational factors, the depressive symptoms score for low education level individuals' was significantly higher than that for high education level, $F(2,597)=5.25, p<0.01$. There was no difference in depression level between single and married individuals. To further explore demographic variables and risk factor differences between the group with depressive symptoms $(n=171)$ and the 
group with non-depressive symptoms $(n=429)$, results indicated that there were no differences between these two groups in age $(t(598)=$ $-0.08, p>0.05)$ or the length of military service $(\mathrm{t}(598)=0.04$, $\mathrm{p}>0.05)$. Moreover, the scores for social-interpersonal stressors $(t$ $(598)=5.69, p<0.01)$ and rejection sensitivity $(t(598)=2.56, p<$ $0.05)$ in the depressive symptoms group were significantly higher than those in the non-depressive symptoms group (Table 1).

\section{Correlations Among Social-interpersonal Stressors, Rejection Sensitivity, and Depressive Symptoms}

A simple correlation analysis revealed that social-interpersonal stressors were positively associated with rejection sensitivity $(r=0.20, p<0.01)$ and depressive symptoms $(r=0.31, p<0.01)$ and that rejection sensitivity was positively correlated with depressive symptoms $(r=0.16, p<0.01)$ (Table 2$)$.

\section{Rejection Sensitivity as a Mediator of the Relationship Between Social-Interpersonal Stressors and Depressive Symptoms}

In the mediation analysis, social-interpersonal stressors were entered as independent variables, depressive symptoms as the dependent variable and rejection sensitivity as the mediator. Table 3 shows that the relationship between social-interpersonal stressors and depressive symptoms is partially mediated by rejection sensitivity $\left(B_{\text {indirect }}=0.02, p<0.001, C I=0.005\right.$ to $0.044)$. The results of structural equation modeling showed that the overall model yielded a satisfactory fit, $\mathrm{CMIN} / \mathrm{DF}=1.374, p=$ $0.24>0.05, \mathrm{GFI}=0.996, \mathrm{AGFI}=0.986, \mathrm{NFI}=0.991, \mathrm{IFI}=0.997$, CFI $=0.997$, and RMSEA $=0.025$. The model explained $10.70 \%$

TABLE 1 | Test of the variable differences between the depressive symptoms and non-depressive symptoms groups.

\begin{tabular}{|c|c|c|c|}
\hline & $\begin{array}{c}\text { Depressive } \\
\text { symptoms group } \\
\text { (N=171) }\end{array}$ & $\begin{array}{c}\text { Non-depressive } \\
\text { symptoms group } \\
\text { (N=429) }\end{array}$ & $T$ \\
\hline & $M \pm S D$ & $M \pm S D$ & \\
\hline 1. Age & $21.77 \pm 2.91$ & $21.79 \pm 3.02$ & -0.08 \\
\hline 2. Length of military service & $3.45 \pm 2.59$ & $3.44 \pm 2.54$ & 0.04 \\
\hline $\begin{array}{l}\text { 3. Social-interpersonal } \\
\text { stressors }\end{array}$ & $15.76 \pm 3.91$ & $13.83 \pm 3.68$ & $5.69^{\star \star}$ \\
\hline 4. Rejection sensitivity & $8.76 \pm 2.93$ & $8.13 \pm 2.66$ & $2.56^{\star \star}$ \\
\hline
\end{tabular}

$M$, means; $S D$, standard deviations.

${ }^{* *} p<0.01$.

TABLE 2 | Means (M), standard deviations (SD), and correlations for all variables.

\begin{tabular}{lrrr}
\hline & $\mathbf{M} \pm \mathbf{S D}$ & $\mathbf{1}$ & $\mathbf{2}$ \\
\hline 1. Social-interpersonal stressors & $14.38 \pm 3.84$ & & \\
2. Rejection sensitivity & $8.38 \pm 2.80$ & $0.20^{\star *}$ & \\
3. Depressive symptoms & $39.08 \pm 7.41$ & $0.31^{\star *}$ & $0.16^{\star *}$ \\
\hline${ }^{* *} p<0.01$. & & &
\end{tabular}

TABLE 3 | Test of the mediation model.

\begin{tabular}{lcccccc}
\hline IV & DV & & Coeff. & SE & & 95\% CI \\
\cline { 3 - 6 } & & & & & LL & UL \\
\hline $\begin{array}{l}\text { Social- } \\
\text { interpersonal } \\
\text { stressors }\end{array}$ & $\begin{array}{l}\text { Depressive } \\
\text { symptoms }\end{array}$ & Total effect & 0.31 & 0.034 & & \\
& & & & & & \\
& & Direct effect & 0.29 & 0.044 & & \\
& & Indirect effect & 0.02 & 0.009 & 0.005 & 0.044
\end{tabular}

$N$, independent variable; $D V$, dependent variable; $C l$, confidence interval; $L L$, lower level; UL, upper level.

of the variance in depressive symptoms $(F(2,597)=35.74, p<$ 0.001) (Figure 1).

\section{DISCUSSION}

The present study evaluated the hypothesis that rejection sensitivity mediates the relationship between socialinterpersonal stressors and depressive symptoms. Before a mediation model could be established, soldiers' depressive symptom situations had to be analyzed.

Our study found that the prevalence of soldiers' depressive symptoms in our cohort was $28.4 \%$, which is higher than the norm, though it was within range of the ratio among Chinese soldiers (14). This finding could be related to the different severities of military deployment exposure in which the adverse effects on mental health were observed $(4,8)$. Moreover, Zung, who developed the Zung Self-Rating Depression Scale (SDS), proposed that the norm of SDS among the Chinese was higher than that from the United States due to cultural diversity (42). Importantly, our results indicated that low education level was a risk factor for more depressive symptoms, consistent with a previous study that determined that a higher education level was related to the capability for psychological adjustment $(7,8)$. There were no significant relationships found in this study sample when marital status, age, and the length of military service were examined as risk factors for depressive symptoms. Compared with the nondepressive symptoms group, the scores for social-interpersonal stressors and rejection sensitivity were significantly higher. Thus, the results certify the viewpoint that depressed military personnel have a markedly elevated level of social-interpersonal stress and rejection sensitivity when they are in more vulnerable circumstances.

Our results confirmed that social-interpersonal stressors have a direct adverse effect on depression symptoms, which is consistent with previous studies. Military personnel are exposed to a great deal of social-interpersonal stressors. Their relationships with leaders, peers, and lovers play a critical role regarding these stressors since soldiers always share living quarters for significant missions or duties during their service period $(20,21)$. Similarly, in the present study, soldiers' mean age was $21.80 \pm 2.99$ years. Regarding life developmental stages, approximately 20 to 40 years of age is considered early 


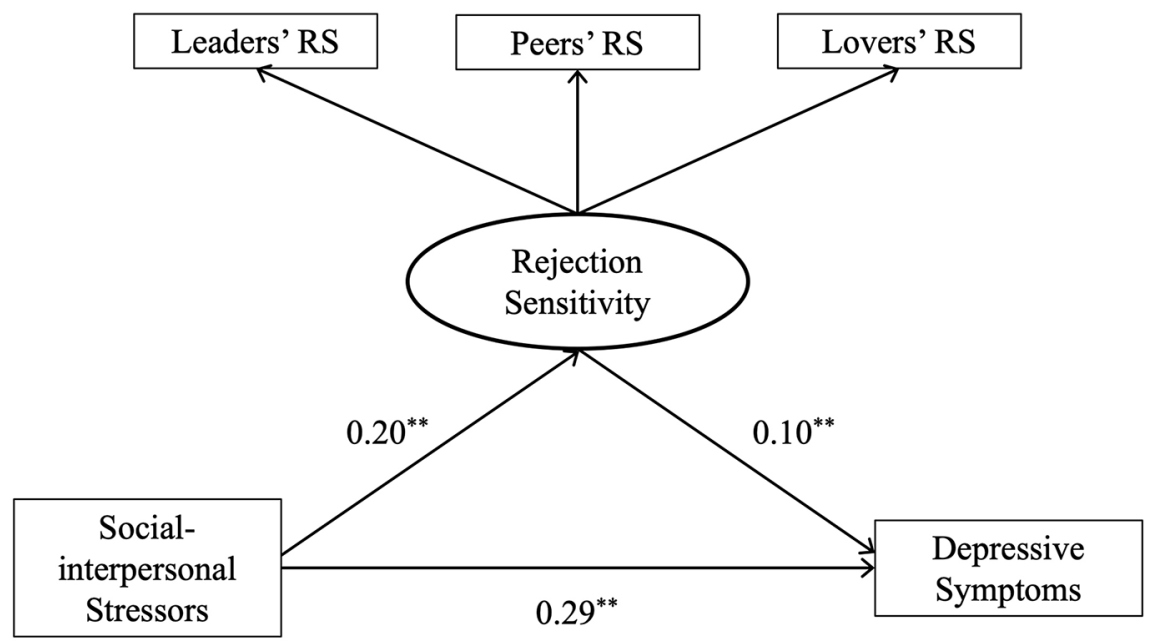

FIGURE 1 | Rejection sensitivity as a mediator through which social-interpersonal stressors increase depressive symptoms. ${ }^{* *} p<0.01$; RS, rejection sensitivity.

adulthood, in which individuals need to resolve their "intimacy vs. isolation" life crises. In other words, they need to develop the capacity for closeness and commitment to others, or otherwise, they will become isolated and alone and will have inability to connect to others in psychologically meaningful ways (44). For young army men, interpersonal relationships are one of the critical skills required for soldiers in the future (45). However, the prevalence of interpersonal violence among soldiers is approximately $16 \%$, and such violence is significantly associated with depression (46).

In military settings, three types of intimate relationships are common: relations with leaders, peers, and lovers. First, to maintain mutual social interactions with leaders, this kind of adaptive relation is based on military leadership in alleviating depression (47) since a strain with the leader will lead to soldiers having less support available to them, increasing social problems and damaging organizational morale and effectiveness, which may undermine mental health (22-24), including depressive symptoms $(25,48,49)$. Additionally, the development of close social ties with peers is helpful in enhancing the sense of belonging and expanding the social networks or social support systems of soldiers; through this protective effect, these bonds with peers buffer depression and improve the mental health of soldiers as well as unit morale (50-54). Finally, a meta-analysis highlighted that, compared with other marital statuses, being married is a protective factor against depression (55) because family function and social support from family are negatively associated with depression in soldiers (56).

Based on previous research, the current study proposed that stressors from leaders, peers, and lovers might elicit depression in soldiers to the extent that rejection sensitivity is increased. These results align with our hypothesis.

According to Beck's cognitive model of depression, once stressful events occur, biased attention, thoughts, rumination, memory, and dysfunctional schemas are consistently linked with the onset and maintenance of depression (57). Social rejection stressors are significantly associated with rejection sensitivity $(58,59)$. The neural dynamics of the rejection sensitivity study showed that under rejection cues, individuals with high rejection sensitivity have decreased activity in the left lateral PFC regions related to cognitive control (60). Additionally, individuals with high rejection sensitivity pay attention to potential rejection cues in a biased manner (61), have schema-congruent information processing biases (62), experience much more rumination (63), and have interpretation biases (64). Consequently, through the distortion effect of rejection sensitivity, people with a high level of social stress experience more depressive symptoms than do those with a low level of social stress $(32,65,66)$.

Social stress evokes the anterior cingulate cortex, which overlaps circuitry with physical pain. This neural alarm system is evolutionarily adaptive for humans (67). When individuals with major depression are confronted with social pain, the rejection sensitivity level would deteriorate, activating the greater amygdala, insula, anterior cingulated cortex in these individuals (68-70). In individuals with a high level of rejection sensitivity, rejection stressors could automatically activate the defensive motivational system (71). This self-protective system tends to make individuals flee or escape from social stress (72), thus helping to predict more depressive symptoms $(73,74)$.

\section{LIMITATIONS AND CONCLUSIONS}

The current study has several limitations. First, data were collected in a sample of nonclinical and predominantly male army recruits. Therefore, the generalization of the findings is limited. In addition, a cross-sectional method was used. Further studies should consider these limitations and focus on the replication of the findings in a prospective longitudinal design with clinical samples.

In military settings, the prevalence of depressive-related disorders or symptoms could be assessed at a higher level than 
in normal populations. Therefore, utilizing validated measures for the early detection of depression, coupled with psychological education, psychological counseling and therapy, and referral to hospitals for antidepressant medication treatment when necessary to maintain the mental fitness of soldiers is imperative. Crucially, morale and unit effectiveness are always emphasized as the priority consideration in the military context. From the perspective of social relationships, determining potential risk factors could prevent episodes of depression. For the individuals who at high rejection sensitivity when encountering social-interpersonal stressors were susceptible to depression. Thus, the metacognition based on psychological education and training should be implemented to intervene, which mainly about how to detect the rejection cues in social interaction with desensitization way and how to self-regulate the biased information and negative emotions related with rejection. This is the first study to assess the relationships among socialinterpersonal stressors, rejection sensitivity and depressive symptoms, and the results showed a partial mediating effect of rejection sensitivity on the association between socialinterpersonal stressors and depressive symptoms. Interventions aimed at decreasing social-interpersonal stressors therefore need to consider rejection sensitivity. Moreover, identifying the risk factors for rejection sensitivity and social stress is important since there is accumulating evidence indicating that both factors have a pernicious effect on depressive symptoms.

\section{DATA AVAILABILITY STATEMENT}

The raw data supporting the conclusions of this article will be made available by the authors, without undue reservation.

\section{REFERENCES}

1. Moussavi S, Chatterji S, Verdes E, Tandon A, Patel V, Ustun B. Depression, chronic diseases, and decrements in health: results from the World Health Surveys. Lancet (2007) 370(9590):851-8. doi: 10.1016/S0140-6736(07)61415-9

2. Vos T, Allen C, Arora M, Barber RM, Bhutta ZA, Brown A, et al. Global, regional, and national incidence, prevalence, and years lived with disability for 310 diseases and injuries, 1990-2015: A systematic analysis for the Global Burden of Disease Study 2015. Lancet (2016) 388(10053):1545-602. doi: 10.1016/S0140-6736(16)31678-6

3. American Psychiatric Association. Diagnostic and Statistical Manual of Mental Disorders. 5th ed. Arlington, VA: American Psychiatric Publishing (2013) p. 160-8.

4. Lyk-Jensen SV, Weatherall CD, Jepsen PW. The effect of military deployment on mental health. Econ Hum Biol (2016) 23:193-208. doi: 10.1016/j.ehb.2016.09.005

5. Mitchell MM, Gallaway MS, Millikan AM, Bell MR. Combat Exposure, Unit Cohesion, and Demographic Characteristics of Soldiers Reporting Posttraumatic Growth. J Loss Trauma (2013) 18:383-95. doi: 10.1080/ 15325024.2013.768847

6. Bartone PT, Vaitkus AM. Dimensions of psychological stress in peacekeeping operations. Mil Med (1998) 163(9):587-93. doi: 10.1093/milmed/163.9.587

7. Bonde JP, Utzon-Frank N, Bertelsen M, Borritz M, Eller NH, Nordentoft M, et al. Risk of depressive disorder following disasters and military deployment: systematic review with meta-analysis. Brit J Psychiat (2016) 208(4):330-6. doi: 10.1192/bjp.bp.114.157859

8. Gadermann A, Engel C, Naifeh J, Nock M, Petukhova M, Santiago P, et al. Prevalence of DSM-IV major depression among U.S. military personnel:

\section{ETHICS STATEMENT}

The studies involving human participants were reviewed and approved by Ethics committee of the army medical university. The patients/participants provided their written informed consent to participate in this study. Written informed consent was obtained from the individual(s) for the publication of any potentially identifiable images or data included in this article.

\section{AUTHOR CONTRIBUTIONS}

JW, XC, and ZF contributed to the design and conception of this study. All authors actively took part in the process. KX, HX, and HW planned and participated in the statistical analysis. JW, XC, and ZF participated in a critical review of the manuscript. All authors read and approved the final manuscript.

\section{FUNDING}

This study was financially supported by Training Program of the Social Science Planning of Chongqing (No.2016PY51) and Natural Science and foreword exploratory Foundation of Chongqing (No. cstc2018jcyjAX0276).

\section{ACKNOWLEDGMENTS}

The authors sincerely thank all the participants for their cooperation.

Meta-analysis and simulation. Mil Med (2012) 177(80):47-59. doi: 10.7205/ milmed-d-12-00103

9. Warner $\mathrm{CH}$, Warner CM, Breitbach J, Rachal J, Matuszak T, Grieger TA. Depression in entry-level military personnel. Mil Med (2007) 172(8):795-9. doi: $10.7205 /$ milmed.172.8.795

10. Ikin JF, McKenzie DP, Gwini SM, Kelsall HL, Creamer M, McFarlane AC, et al. Major depression and depressive symptoms in Australian Gulf war veterans 20 years after the Gulf war. J Affect Disord (2016) 189:77-84. doi: 10.1016/j.jad.2015.09.016

11. Woo SY, Kim HJ, Kim BR, Ahn HC, Jang BN, Park E. Support from superiors reduces depression in Republic of Korea military officers. BMJ Mil Health (2020) 0:1-6. doi: 10.1136/jramc-2019-001343

12. Feng ZZ, Gan LY, Sun H, Pan YH, Liu KY, Liu Y, et al. Epidemiological characteristics of depression in Chinese armymen: a crosssectional study. Acta Acad Med Mil Tert (2013) 35(20):2138-42. doi: 10.16016/j.1000-5404.2013.20.003

13. Feng ZZ. Military Psychology. Beijing: Military Medical Science Press (2009) p. $130-42$.

14. Li J, Li BR, Zhou MX, Ding YL. Advances in research of depression in different groups of Chinese servicemen. Chin J Med Libr Infor Sci (2010) 19(7):14-6. doi: 10.3969/j.issn.1671-3982.2010.07.004

15. Prigerson HG, Maciejewski PK, Rosenheck RA. Population attributable fractions of psychiatric disorders and behavioral outcomes associated with combat exposure among US men. Am J Public Health (2002) 92(1):59-63. doi: 10.2105/ahph.92.1.59

16. Armsden GC, Greenberg MT. The inventory of parent and peer attachment individual differences and their relationship to psychological well-being in adolescence. J Youth Adolesc (1987) 16:427-54. doi: 10.1007/BF02202939 
17. Gotlib IH, Hammen CL. Psychological aspects of depression: toward a cognitive-interpersonal integration. Hoboken,NJ: Wiley \& Sons (1992).

18. Mufson L, Dorta KP. A randomized effectiveness trial of interpersonal psychotherapy for depressed adolescents. Arch Gen Psychiat (2004) 61:57784. doi: 10.1001/archpsyc.61.6.577

19. Rudlph KD, Hammen C, Burge D, Lindberg N, Herzberg D, Daley SE. Toward an interpersonal life-stress model of depression: the developmental context of stress generation. Dev Psychopathol (2000) 12(2):215-34. doi: 10.1017/ S0954579400002066

20. Campbell DJ, Nobel OB. Occupational stressors in military service: a review and framework. Mil Psychol (2009) 21(sup2):S47-67. doi: 10.1080/ 08995600903249149

21. Jonas WB, Connor FG, Deuster P, Macedonia C. Total force fitness for the 21st century a new paradigm. Mil Med (2010) 175(8):88-97. doi: 10.7205/ MILMED-D-10-00280

22. Cacioppo JT, Reis HT, Zautra AJ. Social resilience: The value of social fitness with an application to the military. Am Psychol (2011) 66(1):43-51. doi: $10.1037 / \mathrm{a} 0021419$

23. Russell DW, Benedek DM, Naifeh JA, Fullerton CS, Benevides N, Ursano RJ, et al. Social support and mental health outcomes among U.S. army special operations personnel. Mil Psychol (2016) 28(6):361-75. doi: 10.1037/mil0000114

24. Smitha BN, Vaughna RA, Vogta D, King DW, King LA, Shipherd JC. Main and interactive effects of social support in predicting mental health symptoms in men and women following military stressor exposure. Anxiety Stress Copin (2013) 26(1):52-69. doi: 10.1080/10615806.2011.634001

25. Cox DW, Bakker AM, Naifeh JA. Emotion dysregulation and social support in PTSD and depression: a study of trauma-exposed veterans. J Trauma Stress (2017) 30(5):545-9. doi: 10.1002/jts.22226

26. Monroe SM, Simons AD. Diathesis-stress theories in the context of life stress research: Implications for the depressive disorders. Psychol Bull (1991) 110 (3):406-25. doi: 10.1037//0033-2909.110.3.406

27. Downey G, Feldman SI. Implications of rejection sensitivity for intimate relationships. J Pers Soc Psychol (1996) 70(6):1327-43. doi: 10.1037/00223514.70.6.1327

28. Baumeister R, Leary M. The need to belong desire for interpersonal attachments as a fundamental human motivation. Psychol Bull (1995) 117:497-529. doi: 10.1037/0033-2909.117.3.497

29. Bowlby J. Attachment and loss: Vol. 1. Attachment. New York: Basic Books (1969).

30. London B, Downey G, Bonica C, Paltin I. Social Causes and Consequences of Rejection Sensitivity. J Res Adolesc (2007) 17(3):481-506. doi: 10.1111/j.15327795.2007.00531.x

31. Feldman S, Downey G. Rejection sensitivity as a mediator of the impact of the impact of childhood exposure to family violence on adult attachment behavior. Dev Psychopathol (1994) 6:231-47. doi: 10.1017/S0954579400005976

32. Liu RT, Kraines MA, Massing-Schaffer M, Alloy LB. Rejection sensitivity and depression: mediation by stress generation. Psychiatry (2014) 77(1):86-97. doi: $10.1521 /$ psyc.2014.77.1.86

33. Ng TH, Johnson SL. Rejection Sensitivity is associated with quality of life, psychosocial outcome, and the course of depression in euthymic patients with bipolar I disorder. Cogn Ther Res (2013) 37(6):1169-78. doi: 10.1007/s10608013-9552-1

34. Tops M, Riese H, Oldehinkel AJ, Rijsdijk FV, Ormel J. Rejection sensitivity relates to hypocortisolism and depressed mood state in young women. Psychoneuroendocrino (2008) 33(5):551-9. doi: 10.1016/j.psyneuen. 2008.01.011

35. Gao S, Assink M, Cipriani A, Lin K. Associations between rejection sensitivity and mental health outcomes: A meta-analytic review. Clin Psychol Rev (2017) 57:59-74. doi: 10.1016/j.cpr.2017.08.007

36. Harkness KL, Stewart JG, Wynne-Edwards KE. Cortisol reactivity to social stress in adolescents: role of depression severity and child maltreatment. Psychoneuroendocrino (2011) 36(2):173-81. doi: 10.1016/j.psyneuen.2010.07.006

37. Slavich GM, Donovan A O, Epel ES, Kemeny ME. Black sheep get the blues: a psychobiological model of social rejection and depression. Neurosci Biobehav $R$ (2010) 35(1):39-45. doi: 10.1016/j.neubiorev.2010.01.003

38. Resende LS, Amaral CE, Soares RBS, Alves AS, Alves-dos-Santos L, Britto LRG, et al. Social stress in adolescents induces depression and brain-region- specific modulation of the transcription factor MAX. Transl Psychiat (2016) 6 (10):e914. doi: 10.1038/tp.2016.202

39. Jun YX. The relationship between mental stress and military performance of army soldiers: the moderate effect of army morale. Shannxi: Northwest Normal University (2011).

40. Wei Z. The reliability and validity of Chinese version of the rejection sensitivity questionnaire. Chin J Beh Med BraSci (2012) 21(8):757-9. doi: 10.3760/cma.j.issn.1674-6554.2012.08.027

41. Jia W, Yang XM, Tao W. Mediating effects of social inhibition on the relationship between rejection sensitivity and negative affect in army recruits. Chin J Beh Med BraSci (2017) 26(5):458-61. doi: 10.3760/ cma.j.issn.1674-6554.2017.05.016

42. Sartorius N, Ban TA. Assessment of depression. Berlin: Springer (1986) p. 22132.

43. Dong XW, Lin XW, Hong M. Manual of mental health assessment scales. Beijing: Periodical office of Chinese mental health (1992). p. 195.

44. Gerrig RJ, Zimbardo PG. Psychology and life. Beijing: Posts and Telecom Press (2011).

45. Wisecarver MM, Carpenter TD, Kilcullen RN. Capturing interpersonal performance in a latent performance model. Mil Psychol (2007) 19(2):83101. doi: $10.1080 / 08995600701323376$

46. Cunradi C, Ames G, Moore R. Prevalence and Correlates of Interpersonal Violence Victimization in a Junior Enlisted Navy. Violence Victims (2005) 20 (6):679-94. doi: 10.1891/0886-6708.20.6.679

47. Britt TW, Wright KM, Moore D. Leadership as a predictor of stigma and practical barriers toward receiving mental health treatment a multilevel approach. Psychol Serv (2012) 9(1):26-37. doi: 10.1037/a0026412

48. LaRocca MA, Scogin FR, Hilgeman MM, Smith AJ, Chaplin WF. The impact of posttraumatic growth, transformational leadership, and self-efficacy on PTSD and depression symptom severity among combat Veterans. Mil Psychol (2018) 30(2):162-73. doi: 10.1080/08995605.2018.1425073

49. Jones N, Seddon R, Fear N, McAllister P, Wessely S, Greenberg N. Leadership, cohesion, morale, and the mental health of UK armed forces in Afghanistan. Psychiatry (2012) 71(5), 49-59. doi: 10.1521/psyc.2012.75.1.49

50. Mouthaan J, Euwema MC, Weerts PM. Band of brothers in U.N. Peacekeeping: social bonding among Dutch peacekeeping veterans. Mil Psychol (2005) 2(17):101-14. doi: 10.1207/s15327876mp1702_3

51. Bryan CJ, Heron EA. Belonging protects against postdeployment depression in military presonnel. Depress Anxiety (2015) 32(5):349-55. doi: 10.1002/ da. 22372

52. Hatch SL, Harvey SB, Dandeker C, Burdett H, Greenberg N, Fear NT, et al. Life in and after the Armed Forces: social networks and mental health in the UK military. Sociol Health Ill (2013) 35(7):1045-64. doi: 10.1111/14679566.12022

53. Charbonneau D, Wood VM. Antecedents and outcomes of unit cohesion and affective commitment to the army. Mil Psychol (2018) 30(1):43-53. doi: $10.1080 / 08995605.2017 .1420974$

54. Smith AJ, Benight CC, Cieslak R. Social support and postdeployment coping self-efficacy as predictors of distress among combat veterans. Mil Psychol (2017) 25(5):452-61. doi: 10.1037/mil0000013

55. Yan XY, Huang SM, Wu WH, Qin Y. Marital status and risk for late life depression: a meta-analysis of the published literature. J Int Med Res (2011) 39:1142-54. doi: 10.1177/147323001103900402

56. Collins CL, Lee K, MacDermid Wadsworth SM. Family stressors and resources: relationships with depressive symptoms in military couples during pre-deployment. Fam Relat (2017) 66(2):302-16. doi: 10.1111/ fare. 12251

57. Disner SG, Beevers CG, Haigh EAP, Beck AT. Neural mechanisms of the cognitive model of depression. Nat Rev Neurosci (2011) 12(8):467-77. doi: $10.1038 / \mathrm{nrn} 3027$

58. Wang J, McDonald KL, Rubin KH, Laursen B. Peer rejection as a social antecedent to rejection sensitivity in youth: The role of relational valuation. Pers Indiv Differ (2012) 53(7):939-42. doi: 10.1016/j.paid.2012.07.007

59. Rowe SL, Gembeck MJZ, Rudolph J, Nesdale D. A longitudinal study of rejecting and autonomy-restrictive parenting, rejection sensitivity, and aocioemotional aymptoms in early adolescents. J Abnorm Child Psych (2015) 43(6):1107-18. doi: 10.1007/s10802-014-9966-6 
60. Kross E, Egner T, Ochsner K, Hirsch J, Downey G. Neural dynamics of rejection sensitivity. J Cogn Neurosci (2007) 19(6):945-56. doi: 10.1162/jocn.2007.19.6.945

61. Berenson KR, Gyurak A, Ayduk Ö, Downey G, Garner MJ, Mogg K, et al. Rejection sensitivity and disruption of attention by social threat cues. J Res Pers (2009) 43(6):1064-72. doi: 10.1016/j.jrp.2009.07.007

62. Mor N, Inbar M. Rejection sensitivity and schema-congruent information processing biases. J Res Pers (2009) 43(3):392-8. doi: 10.1016/j.jrp.2009.01.001

63. Pearson KA, Watkins ER, Mullan EG. Rejection sensitivity prospectively predicts increased rumination. Behav Res Ther (2011) 49(10):597-605. doi: 10.1016/j.brat.2011.06.004

64. Normansell KM, Wisco BE. Negative interpretation bias as a mechanism of the relationship between rejection sensitivity and depressive symptoms. Cognit Emot (2017) 31(5):950-62. doi: 10.1080/02699931.2016.1185395

65. Norona JC, Roberson PNE, Welsh DP. Rejection sensitivity and depressive symptoms: Longitudinal actor-partner effects in adolescent romantic relationships. J Adolesc (2016) 51:6-18. doi: 10.1016/j.adolescence.2016.05.007

66. De Rubeis J, Lugo RG, Witthöft M, Sütterlin S, Pawelzik MR, Vögele C. Rejection sensitivity as a vulnerability marker for depressive symptom deterioration in men. PLoS One (2017) 12(10):e185802. doi: 10.1371/ journal.pone.0185802

67. Eisenberger NI, Lieberman MD. Why rejection hurts: a common neural alarm system for physical and social pain. Trends Cognit Sci (2004) 8(7):294-300. doi: 10.1016/j.tics.2004.05.010

68. Kumar P, Waiter GD, Dubois M, Milders M, Reid I, Steele JD. Increased neural response to social rejection in major depression. Depress Anxiety (2017) 34(11):1049-56. doi: 10.1002/da.22665

69. Masten CL, Eisenberger NI, Borofsky LA, McNealy K, Pfeifer JH, Dapretto M. Subgenual anterior cingulate responses to peer rejection: A marker of adolescents' risk for depression. Dev Psychopathol (2011) 23(1):283-92. doi: 10.1017/S0954579410000799

70. Ehnvall A, Mitchell PB, Hadzi-Pavlovic D, Malhi GS, Parker G. Pain during depression and relationship to rejection sensitivity. Acta Psychiat Scand (2009) 119(5):375-82. doi: 10.1111/j.1600-0447.2008.01316.x

71. Downey G, Mougios V, Ayduk O, London BE, Shoda Y. Rejection Sensitivity and the Defensive Motivational System. Psychol Sci (2004) 15(10):668-73. doi: 10.1111/j.0956-7976.2004.00738.x

72. Lang P, Davis M. Fear and anxiety: Animal models and human cognitive psychophysiology. J Affect Disord (2000) 61:137-59. doi: 10.1016/S0165-0327 (00)00343-8

73. Zhang LY, Xu Y, Chen Z. Effects of the behavioral inhibition system (BIS), behavioral activation system (BAS), and emotion regulation on depression: A one-year follow-up study in Chinese adolescents. Psychiat Res (2015) 230 (2):278-93. doi: 10.1016/j.psychres.2015.09.007

74. Gladstone GL, Parker GB. Is behavioral inhibition a risk factor for depression? J Affect Disord (2006) 95(1-3):85-94. doi: 10.1016/j.jad.2006.04.015

Conflict of Interest: The authors declare that the research was conducted in the absence of any commercial or financial relationships that could be construed as a potential conflict of interest.

Copyright (c) 2020 Wang, Cheng, Xu, Xu, Wang and Feng. This is an open-access article distributed under the terms of the Creative Commons Attribution License (CC $B Y)$. The use, distribution or reproduction in other forums is permitted, provided the original author(s) and the copyright owner(s) are credited and that the original publication in this journal is cited, in accordance with accepted academic practice. No use, distribution or reproduction is permitted which does not comply with these terms. 